\title{
ROTEIRO “CAMINHOS DE GRAVATÁ": TURISMO RURAL PEDAGÓGICO NO MUNICÍPIO DE GRAVATAL - SANTA CATARINA
}

\section{ITINERARY “GRAVATÁ PATHS": PEDAGOGICAL RURAL TOURISM IN GRAVATAL - SANTA CATARINA}

\begin{abstract}
Francine Lunardi Calegari

Acadêmica do curso de Geografia. Unesc. E-mail: francinetms14@gmail.com

Juliana Debiassi Menegasso

Doutoranda no Programa de Pós-Graduação em Ciências Ambientais PPGCA. Unesc. E-mail: julianaorleans@gmail.com

\section{Nilzo Ivo Ladwig}

Professor da disciplina de Planejamento Urbano e Regional - Unesc-Doutor em Engenharia Civil - UFSC. E-mail: ladwig@unesc.net

\section{Andréa Rabelo Marcelino}

Professora da disciplina de Estágio III do curso de Geografia- LicenciaturaUnesc - Mestra em Educação. Unesc. E-mail: armarcelino@unesc.net
\end{abstract}

\section{Adriano de Oliveira Dias}

Professor da disciplina de Estágio III do curso de Geografia-LicenciaturaUnesc - Mestre em Ciências Ambientais. Unesc. E-mail:

\section{RESUMO}

O turismo rural pedagógico é uma ferramenta metodológica, que utiliza as realidades do campo, recursos naturais e culturais para a promoção de uma educação extracurricular. $\mathrm{O}$ trabalho tem como objetivo propor um roteiro de turismo rural pedagógico denominado Caminhos de Gravatá no município de Gravatal, estado de Santa Catarina. A metodologia consistiu em levantamento de dados bibliográficos, documentais, reconhecimento em campo e levantamento fotográfico. Posteriormente, foi criado o roteiro com base nos componentes curriculares e nas habilidades da Base Nacional Comum Curricular (BNCC), considerando como público alvo os alunos do ensino fundamental. $\mathrm{O}$ roteiro proposto possui nove locais potenciais, sendo: duas sedes de propriedades com práticas agropecuárias e sete outros pontos distribuídos no espaço rural. Percebeu-se que o município apresenta potencial para a prática do turismo rural pedagógico, com belezas naturais, aspectos culturais e históricos. Pretende-se após a conclusão deste trabalho criar novos roteiros pedagógicos que possam abranger outras áreas do município e atender um público diferenciado.

Palavras-chave: Educação; Espaço Rural; Base Nacional Comum Curricular.

\section{ABSTRACT}

Pedagogical rural tourism is a methodological tool that uses the realities of the countryside, natural and cultural resources to promote extracurricular education. The work aims to propose an educational rural tourism itinerary called Caminhos de Gravatá in the city of Gravatal, state of Santa Catarina. The methodology consisted of collecting bibliographic, documentary data, field recognition and photographic survey. Subsequently, the script was created based on the curricular components and the skills of the National Common Curriculum Base (BNCC), considering the target audience of elementary school students. The proposed itinerary has nine potential locations, being: two headquarters of properties with agricultural practices and seven other points distributed in the rural space. It was noticed that the municipality has potential for the practice of pedagogical rural tourism, with natural beauty, cultural and historical aspects. After the conclusion of this work, the intention is to create new pedagogical itineraries that can cover other areas of the municipality and serve a different audience.

Keywords: Education; Rural Space; Common national curriculum base. 


\section{INTRODUÇÃO}

A pesquisa desenvolveu-se no município de Gravatal, localizado no sul do estado de Santa Catarina. O setor com maior rentabilidade no município é a prestação de serviços, responsável por $25 \%$ do PIB, seguida pelos outros setores, educação, saúde, administração, agropecuária e indústrias (SEBRAE, 2016). O município é historicamente turístico, com fontes de águas hidrominerais, passeios ecológicos, camping, terapias naturais e uma vasta diversidade de passeios no espaço rural.

Segundo Cruz (2003), desde as primeiras formas de fazer turismo até hoje em dia, a definição do que é turismo muda constantemente devido a dinamicidade da sociedade. $\mathrm{O}$ conceito de turismo pela Organização Mundial do Turismo, interpretado por Cruz (2003), é o deslocamento em busca de lazer, saúde, educação, religiosidade e outros, que ocorre no espaço diferente do seu habitual ou rotineiro, que utiliza algum meio de transporte e ao menos um pernoite no local de destino. Neste sentido, viagem e turismo são sinônimos.

Outra denominação de turismo é dada por Cruz (2003), que trata o turismo como uma prática social, determinada pela cultura e pelos momentos vividos da sociedade, sendo o espaço geográfico o principal objeto de consumo. Andrade (2000, p. 38) compara o turismo como "um produto composto por uma combinação de bens e serviços" da sociedade de consumo atual. Cuja sua funcionalidade ou segmentação varia conforme os "requisitos da oferta e das exigências da demanda". O autor faz a sua própria conceituação de que "turismo é o complexo de atividades e serviços relacionados aos deslocamentos, transportes, alojamentos, alimentação, circulação de pessoas produtos típicos, atividades relacionadas aos movimentos culturais, visitas, lazer e entretenimento".

O turismo necessita ser dividido em segmentos para sua organização, planejamento, gestão e marketing. Estes segmentos podem ser definidos pela identidade da oferta, características e variáveis da demanda, território onde ele ocorre, práticas e tradições. Agroturismo, ecoturismo, turismo cultural, turismo urbano, turismo de aventura, turismo religioso, turismo rural e diversos outros, cada qual com suas especificidades (BRASIL, 2006), são alguns dos segmentos turísticos.

O turismo atua em diversos espaços, entre eles o rural. Silva et al. (1998), interpretam o turismo no espaço rural como sendo uma atividade que abrange toda e qualquer forma de turismo, com pernoite ou não, cada segmento com o seu objetivo, que podem ou não estar 
associados a alguma prática rural. "Assim, entende-se turismo no espaço rural como um recorte geográfico" (BRASIL, 2003, p.11), onde o turismo rural está inserido.

Brasil (2003, p. 11) conceitua turismo rural como “[...] o conjunto de atividades turísticas desenvolvidas no meio rural, comprometido com a produção agropecuária, agregando valor a produtos e serviços", essa forma de turismo também faz uso das tradições e modos de vida existentes nas propriedades rurais.

No espaço rural é notável a biodiversidade, a cultura dos modos de produção, a paisagem e a produção de qualidade (BRASIL, 2006), características estas que Gravatal possui, com famílias que conservam as tradições de engenhos, plantio, patrimônios materiais e destaque na quantidade de cachoeiras e belas paisagens.

O turismo pode significar uma diversificação de renda e a oportunidade de emprego para as comunidades rurais. Em função do uso turístico, estes locais podem receber melhorias em infraestrutura e consequentemente melhorar a qualidade de vida (CRUZ, 2003).

Esse conjunto de características do turismo rural se funde na modalidade de turismo rural pedagógico, considerada uma ferramenta para auxiliar no processo de aprendizagem dos alunos (SILVEIRA et al., 2008; SCREMIN; JUNQUEIRA, 2012).

O turismo pedagógico é uma ferramenta que permite demonstrar na prática, a teoria da sala de aula, podendo ser realizado no campo, levando os estudantes a vivenciarem situações do cotidiano, adquirirem novos conhecimentos e informações sobre o espaço rural (PERINOTTO, 2008). Matos (2012) afirma que o turismo pedagógico seria o estudo do meio, aplicado por educadores que estendem seu trabalho para além da sala de aula. Desta forma, quando os estudantes adquirem inicialmente o conteúdo dentro da sala de aula e conseguem visualizar esse conhecimento na sua realidade, seja no município ou na região que moram, se interessam cada vez mais a aprender.

O turismo pedagógico que permeia as realidades rurais recebe o nome de turismo rural pedagógico, conceituado pelos autores Klein, Troian e Souza (2011), por uma forma de turismo com objetivo pedagógico no âmbito do espaço rural relacionadas às práticas agropecuárias, utilizando as realidades do campo, recursos naturais e culturais para a melhoria da qualidade de ensino, promoção de projetos, conscientização e educação ambiental.

Outro ponto importante, segundo Zanoni e Stefano (2004, s/p), é que “existem crianças que foram criadas no meio urbano que nunca viram uma vaca, um cavalo, uma cabra, uma galinha entre outros animais [...]”. Assim, muitas vezes não têm a oportunidade de 
conhecer a origem dos derivados desses animais, somente tendo contato com o produto embalado em uma prateleira de supermercado.

O roteiro de turismo rural pedagógico de Gravatal tem como conteúdos norteadores os objetos de conhecimento da Base Nacional Comum Curricular (BNCC). A BNNC é um documento recente do ano de 2017, criada com o objetivo de nortear as aprendizagens essenciais que todos os estudantes da educação básica de escolas públicas e privadas devem seguir em todas as etapas (BRASIL, 2017).

Segundo a Federação Catarinense de Municípios (FECAM, 2019), a atividade turística rendeu ao município de Gravatal o valor de $\mathrm{R} \$ 2.473 .527$ no ano de 2017. Contudo, no complexo hidrotermal está a maior parte da arrecadação, mas de certa forma o município como um todo se beneficia. A partir disto, o turismo rural pedagógico se apresenta como alternativa para a comunidade local, tanto em termos econômicos, como na preservação do seu patrimônio natural e cultural. $\mathrm{O}$ trabalho tem como objetivo geral propor um roteiro de turismo rural pedagógico para o ensino fundamental no município de Gravatal alinhado componentes curriculares e as habilidades da BNCC.

\section{LOCALIZAÇÃO E CARACTERIZAÇÃO DA ÁREA DE ESTUDO}

O município de Gravatal localizado ao sul do estado de Santa Catarina e possui uma área de 165,718 km² (Figura 1). Nele, estimasse 11.577 habitantes (IBGE, 2020), sendo que em 2010, 58\% residiam na área urbana e 42\% na área rural. (IBGE, 2010).

Figura 1 - Mapa de localização do município de Gravatal

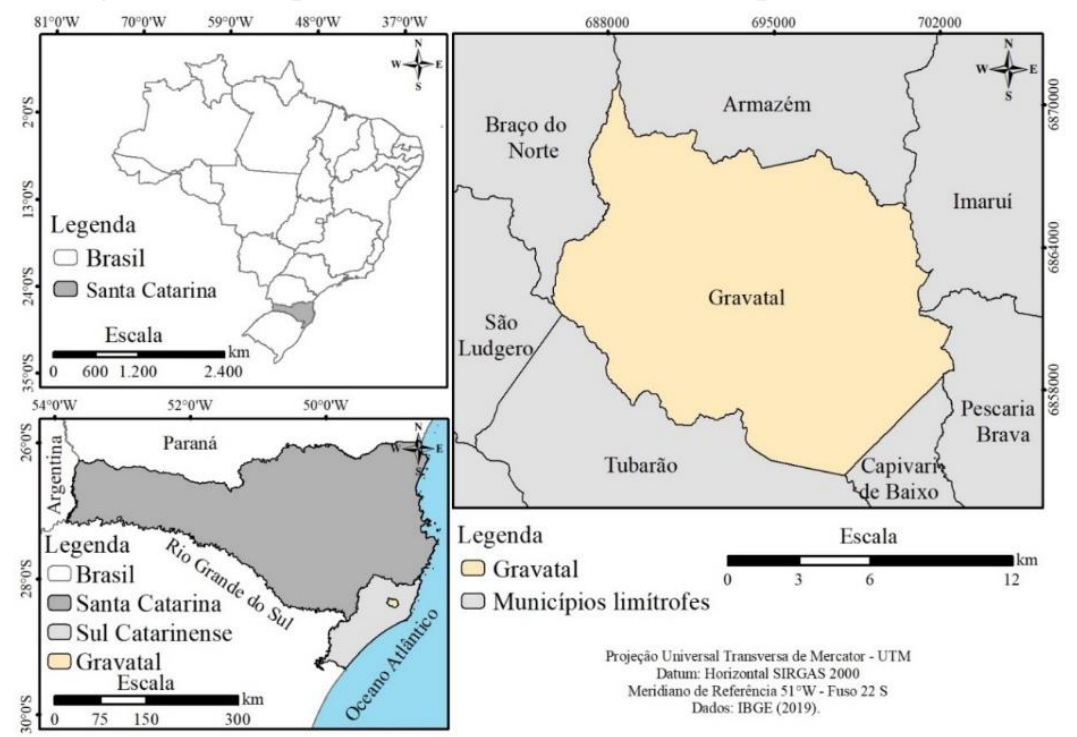

Fonte: os autores, 2020. 
O tipo climático do município, segundo a classificação de Köppen, é Cfa caracterizado como "Subtropical mesotérmico úmido e verão quente", com temperatura média anual entre $18^{\circ} \mathrm{C}$ e $27^{\circ} \mathrm{C}$ (GRAVATAL, 2014).

Em relação aos aspectos hidrográficos, a área do município de Gravatal, insere-se na sub-bacia do rio Capivari pertencente a bacia hidrográfica do rio Tubarão e Complexo Lagunar. O curso de rio principal que percorre o município de Gravatal de leste a oeste é o rio Gravatal ou Caipora, afluente da margem esquerda do rio Capivari, que por sua vez desemboca na margem direita do Rio Tubarão (SANTA CATARINA, 2002). O rio Gravatal tem como afluentes os rios: Ângulo; Caetê; Indaial de Cima; Batateiras, Rio das Antas e Córrego São Bento (GRAVATAL, 2014).

O município de Gravatal está inserido no domínio da Mata Atlântica, cobertura vegetal original denominada Floresta Ombrófila Densa, caracterizada por vegetação de espécies variadas, alta (20-30m de altura), densa, com árvores perenifólias, que recobria a porção leste do estado, entre o planalto e o oceano, constituída de planícies litorâneas e encostas íngremes da Serra do Mar e da Serra Geral (VEADO; PIMENTA, 2016). Atualmente, em decorrência da ação antrópica, grande parte da Floresta Ombrófila Densa foi substituída, sendo constituída, em sua maioria, por remanescentes florestais em estágio secundário de regeneração (VIBRANS et al., 2012; LINGNER et al., 2015).

A área do município de Gravatal faz parte do grande território de ocupações de dos povos caçadores e coletores, que usufruíram das condições naturais para sua sobrevivência em um amplo espaço geográfico, há mais de 8000 anos. Entre os povoamentos mais recentes, destacam-se os ceramistas Xokleng, caracterizados como populações nômades e com muita relação com a terra. Outro grupo de indígenas, formado pela nação Tupi-Guarani, colonizou as várzeas dos rios e a planície costeira do Sul do Brasil há aproximadamente 2000 anos (SCHMITZ, 2013; FARIAS, 2005).

A colonização por não indígenas em Gravatal começa a se desenvolver por volta do século XIX com a chegada dos açorianos e portugueses que habitavam a Colônia de Santo Antônio dos Anjos da Laguna (atual município de Laguna), já colonizada por portugueses em 1842. Em seguida, entre 1880 e 1885, a colonização alemã e por volta de 1900 iniciouse a colonização italiana. Com a chegada das famílias italianas Zappelini, Lunardi, Estevão Grasso fundou-se a colônia de São Miguel (TRAVASSOS; PALMEIRA, 1992; DUARTE, 2001). 
Após a vinda dos imigrantes alemães e italianos, inicia-se o comércio com a colônia de Laguna e Tubarão. A partir disto, as terras férteis foram destinadas principalmente para o plantio da cana-de-açúcar e da mandioca, que eram comercializadas posteriormente com a colônia de Laguna (CAMPOS, 2011).

O grande destaque deste período lembrado, até hoje pelos moradores de Gravatal, é a existência do antigo Porto Fluvial no leito do Rio Capivari, ligando a Serra com Laguna. Salvador (2019) enfatiza que o porto foi importante para o escoamento dos produtos agrícolas, além do transporte de pessoas para região próxima entre o final do século XIX e começo do século XX.

Com a expansão das moradias constatou-se a presença de águas jorrantes no leito do rio, em 1942 e a descoberta das águas minerais de alto poder radioativo, com qualidades medicinais e com uma temperatura de 37 graus (TRAVASSOS; PALMEIRA, 1992). Com isso, iniciou-se o engajamento do município no ramo turístico, com a implementação de um complexo para a exploração da água e o setor hoteleiro para recepcionar os futuros turistas.

\section{MATERIAL E MÉTODOS}

Para a realização deste trabalho, foram adotados dois procedimentos metodológicos. Inicialmente, foram feitas pesquisas bibliográficas e documentais, referentes ao tema e para conhecimento da área em estudo, como análises de artigos, dissertações, livros e mapas.

Num segundo momento, foi realizada pesquisa de campo, sendo esta, dividida em duas etapas que consistiram em seis visitas técnicas. Na primeira etapa houve o reconhecimento da área estudada e identificação dos possíveis pontos de interesse: a Nascente, o Mirante, a Gruta Nossa Senhora da Saúde, a Pedra do Índio, Cachoeira de São Miguel, Casarão e a Central de Captação de Água de Gravatal.

$\mathrm{Na}$ etapa 2, foi feita uma nova saída a campo, na propriedade Casa do Mel e Pousada Vô Juca, onde, além do reconhecimento da área, houve uma conversa com os proprietários.

É importante destacar que paralelamente à saída a campo, foram demarcados os pontos para obtenção das coordenadas geográficas e registros fotográficos dos locais visitados.

$\mathrm{Na}$ estruturação do roteiro foi utilizado o documento que rege a Base Nacional Comum Curricular (BNCC), considerando como público alvo estudantes do Ensino Fundamental anos iniciais e finais. Desta forma, foram apontados alguns componentes curriculares e habilidades a serem desenvolvidas para cada nível de ensino. O componente 
curricular Língua Inglesa não foi contemplado nesta pesquisa, por ser obrigatório somente a partir do $6^{\circ}$ Ano (Anos Finais). Salienta-se que demais componentes curriculares e habilidades, bem como algumas sugestões de trabalho que poderão ser realizadas, foram disponibilizadas no link a seguir:

https://drive.google.com/file/d/1Gd80SM8yI1iMtd6rgQFtFDqGHpS2vXf7/view?usp=shari ng

$\mathrm{Na} \mathrm{BNCC}$, as habilidades são identificadas por um código alfanumérico, conforme Figura 2.

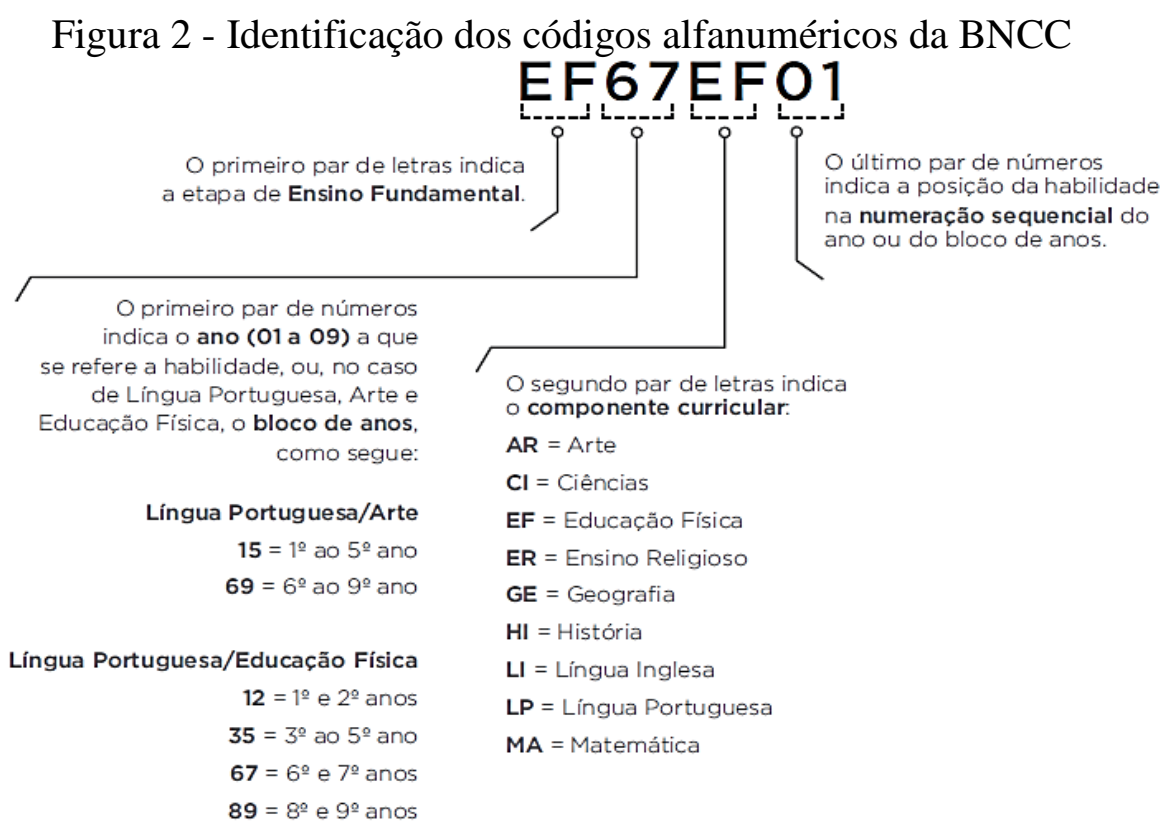

Fonte: Brasil, 2017.

Cabe ressaltar, que a proposta de roteiro não é restrita somente para a o Ensino Fundamental, ela pode ser aplicada e adaptada para outros níveis de ensino, como a Educação Infantil, o Ensino Médio e até mesmo o Ensino Superior.

\section{DISCUSSÃO DOS RESULTADOS}

Durante o trabalho de campo foram demarcados nove pontos propícios à prática de turismo rural pedagógico, localizados na Figura 3.

\section{Casa do Mel Bioápis}

A Casa do Mel Bioápis é uma propriedade familiar com área total de nove hectares, sendo quatro hectares de mata preservada. Na propriedade desenvolve-se a apicultura e a produção de extrato de tomate orgânico.

No que tange a Apicultura, é praticada com a criação das abelhas africanizadas, com ferrão e agressivas (PEREIRA et al., 2003). Já na produção de extrato de tomate são 
utilizados frutos cultivados nos municípios de Tubarão e Urubici, sendo que na propriedade é realizado todo o processo de produção do extrato de tomate. No local também há atividades de Turismo Rural, ainda incipiente, mas que quando recebem turistas consegue comercializar os produtos produzidos pela família, na própria propriedade.

É importante ressaltar que a propriedade faz parte do projeto de agroturismo, conhecido como Acolhida na Colônia, de uma rota gastronômica, a Rota Caminhos e Sabores e uma associação, a AGRECO (Associação dos Agricultores Ecológicos das Encostas da Serra Geral), que têm como objetivos incentivar e fortalecer a prática da agricultura familiar nos municípios catarinenses, auxiliar na produção, comercialização e divulgação das propriedades.

Figura 3 - Pontos do roteiro do turismo rural pedagógico em Gravatal

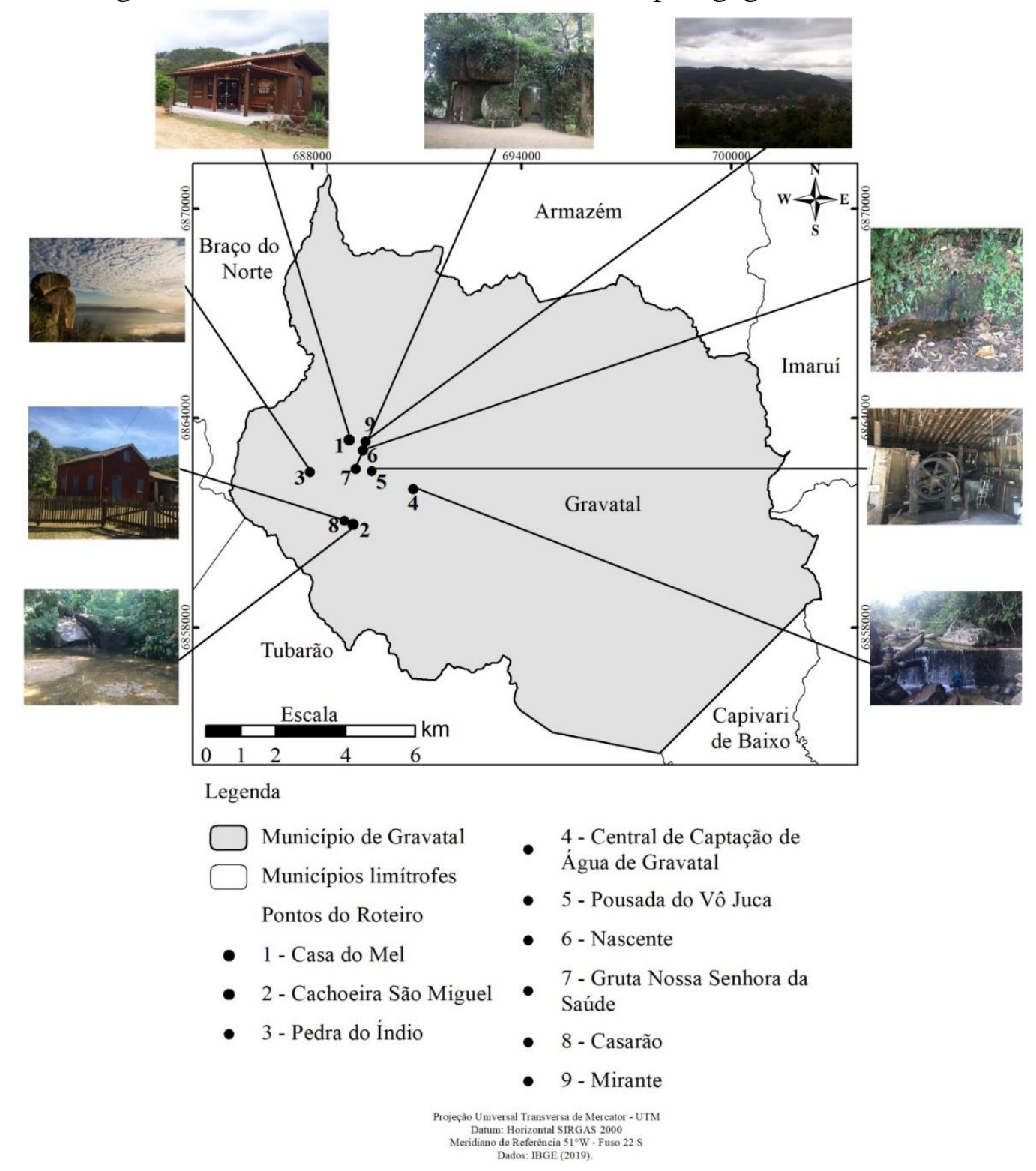

Fonte: os autores, 2020. 
Por meio da visita foram pontuadas algumas propostas de componentes curriculares e habilidades a serem desenvolvidas pelas escolas ao visitarem a Casa do Mel, sintetizadas no Quadro 1.

Quadro 1 - Síntese dos componentes curriculares, habilidades que podem ser desenvolvidos na Casa do Mel Bioápis

\begin{tabular}{|c|c|c|}
\hline \multirow{2}{*}{$\begin{array}{l}\text { Componente } \\
\text { curricular }\end{array}$} & \multicolumn{2}{|c|}{ Habilidades } \\
\hline & Anos Iniciais & Anos Finais \\
\hline $\begin{array}{c}\text { Língua } \\
\text { Portuguesa }\end{array}$ & $\begin{array}{l}\text { (EF01LP23) Planejar e produzir, em } \\
\text { colaboração com os colegas e com a ajuda } \\
\text { do professor, entrevistas, curiosidades, } \\
\text { dentre outros gêneros do campo } \\
\text { investigativo, que possam ser repassados } \\
\text { oralmente por meio de ferramentas } \\
\text { digitais, em áudio ou vídeo, considerando } \\
\text { a situação comunicativa e o } \\
\text { tema/assunto/finalidade do texto. }\end{array}$ & $\begin{array}{l}\text { (EF69LP36) Produzir, revisar e editar } \\
\text { textos voltados para a divulgação do } \\
\text { conhecimento e de dados e resultados de } \\
\text { pesquisas, tais como artigos de divulgação } \\
\text { científica, verbete de enciclopédia, } \\
\text { infográfico, infográfico animado, podcast } \\
\text { ou vlog científico, relato de experimento, } \\
\text { relatório, relatório multimidiático de } \\
\text { campo, dentre outros, considerando o } \\
\text { contexto de produção e as regularidades } \\
\text { dos gêneros em termos de suas } \\
\text { construções composicionais e estilos. }\end{array}$ \\
\hline Geografia & $\begin{array}{l}\text { (EF04GE04) Reconhecer especificidades } \\
\text { e analisar a interdependência do campo e } \\
\text { da cidade, considerando fluxos } \\
\text { econômicos, de informações, de ideias e } \\
\text { de pessoas. }\end{array}$ & $\begin{array}{l}\text { (EF07GE06) Discutir em que medida a } \\
\text { produção, a circulação e o consumo de } \\
\text { mercadorias provocam impactos } \\
\text { ambientais, assim como influem na } \\
\text { distribuição de riquezas, em diferentes } \\
\text { lugares. }\end{array}$ \\
\hline Ciências & $\begin{array}{l}\text { (EF05CI09) Discutir a ocorrência de } \\
\text { distúrbios nutricionais (como obesidade, } \\
\text { subnutrição etc.) entre crianças e jovens a } \\
\text { partir da análise de seus hábitos (tipos e } \\
\text { quantidade de alimento ingerido, prática } \\
\text { de atividade física etc.). }\end{array}$ & $\begin{array}{l}\text { (EF06CI02) Identificar evidências de } \\
\text { transformações químicas a partir do } \\
\text { resultado de misturas de materiais que } \\
\text { originam produtos diferentes dos que } \\
\text { foram misturados (mistura de ingredientes } \\
\text { para fazer um bolo, mistura de vinagre } \\
\text { com bicarbonato de sódio etc.). }\end{array}$ \\
\hline
\end{tabular}

Fonte: os autores, 2020.

\section{Cachoeira São Miguel}

De acordo com o mapeamento geológico da folha Criciúma, realizado pelo CPRM (2000), a Cachoeira São Miguel faz parte de um conjunto de rochas magmáticas plutônicas, com idade em torno de 600 milhões de anos (Era Neoproterozóico), originada pelo resfriamento e consolidação do magma, rico em sílica $\left(\mathrm{SiO}_{2}\right)$, em grande profundidade na Terra, formando um grande corpo intrusivo, que posteriormente foi exposto na superfície, bem típico no município.

Este corpo constitui-se em uma intrusão no Complexo Granítico-Gnáissico do Escudo Catarinense (grupo de rochas mais antigas do Estado). O Granito Imaruí-Capivari faz parte do agrupamento de rochas denominado Suíte Pedras Grandes, integrante do Cinturão Dom 
Feliciano-Batólito de Florianópolis. Apresentam-se de cor cinza a rosa, com cristais maiores (CPRM, 2000).

Para se chegar a Cachoeira São Miguel é necessário fazer uma trilha de aproximadamente 200 metros em meio a mata, localizada em uma propriedade particular. $\mathrm{Na}$ saída à campo, foram observados alguns impactos, decorrentes da abertura da trilha de acesso e da captação de água, como a presença de resíduos sólidos e vestígios de fogueira. No Quadro 2 estão sintetizadas as propostas componentes curriculares e habilidades para a Cachoeira São Miguel.

Quadro 2 - Síntese dos componentes curriculares, habilidades que podem ser desenvolvidos na Cachoeira São Miguel

\begin{tabular}{|c|l|lc|}
\hline \multirow{2}{*}{$\begin{array}{c}\text { Componente } \\
\text { curricular }\end{array}$} & \multicolumn{1}{|c|}{ Habilidades } \\
\cline { 2 - 4 } Matemática & $\begin{array}{l}|c| \\
\text { (EF03MA12) Descrever e representar, por } \\
\text { meio de esboços de trajetos ou utilizando } \\
\text { croquis e maquetes, a movimentação de } \\
\text { pessoas ou de objetos no espaço, incluindo } \\
\text { mudanças de direção e sentido, com base } \\
\text { em diferentes pontos de referência. }\end{array}$ & $\begin{array}{l}\text { (EF06MA28) Interpretar, descrever } \\
\text { desenhar plantas baixas simples } \\
\text { residências e vistas aéreas. }\end{array}$ \\
\hline \multirow{5}{*}{ Geografia } & $\begin{array}{l}\text { (EF02GE11) Reconhecer a importância do } \\
\text { solo e da água para a vida, identificando } \\
\text { seus diferentes usos (plantação e extração } \\
\text { de materiais, entre outras possibilidades) e } \\
\text { os impactos desses usos no cotidiano da } \\
\text { cidade e do campo. }\end{array}$ & $\begin{array}{l}\text { (EF06GE05) Relacionar } \\
\text { climáticos, tipos de solo, relevo formações } \\
\text { vegetais. }\end{array}$ \\
\hline \multirow{5}{*}{ Ciências } & $\begin{array}{l}\text { (EF02CI04) Descrever características de } \\
\text { plantas e animais (tamanho, forma, cor, fase } \\
\text { da vida, local onde se desenvolvem etc.) } \\
\text { que fazem parte de seu cotidiano e } \\
\text { relacioná-las ao ambiente em que eles } \\
\text { vivem. }\end{array}$ & $\begin{array}{l}\text { (EF06CI12) Identificar diferentes tipos de } \\
\text { rocha, relacionando a formação de fósseis a } \\
\text { rochas sedimentares em diferentes períodos } \\
\text { geológicos. }\end{array}$ \\
\hline
\end{tabular}

Fonte: os autores, 2020.

\section{Pedra do Índio}

A trilha que dá acesso a Pedra do Índio tem aproximadamente $3 \mathrm{~km}$ de extensão, cercada por lendas e histórias contadas pela comunidade local. O nome "Pedra do Índio" é assim denominado, pois no local existiam muitos vestígios da cultura material indígena, além de pinturas rupestres, que foram deterioradas por pessoas que visitavam o local.

A Pedra do Índio é corpo rochoso da formação Granito Imaruí- Capivari. Do local tem-se uma vista que contempla da paisagem, desde o planalto até o litoral, toda a extensão da cidade de Gravatal encaixada em um vale, além de diversas formações do relevo. Pode-se observar neste local o nascer e o pôr do sol.

No Quadro 3 foram sintetizados alguns componentes curriculares e habilidades que podem ser desenvolvidos na Pedra do Índio. 
Quadro 3 - Síntese dos componentes curriculares e habilidades que podem ser desenvolvidos na Pedra do Índio

\begin{tabular}{|c|c|c|}
\hline \multirow{2}{*}{$\begin{array}{l}\text { Componente } \\
\text { curricular }\end{array}$} & \multicolumn{2}{|c|}{ Habilidades } \\
\hline & Anos Iniciais & $\begin{array}{c}\text { Anos Finais } \\
\end{array}$ \\
\hline Artes & $\begin{array}{l}\text { (EF15AR25) Conhecer e valorizar o } \\
\text { patrimônio cultural, material e imaterial, de } \\
\text { culturas diversas, em especial a brasileira, } \\
\text { incluindo-se suas matrizes indígenas, } \\
\text { africanas e europeias, de diferentes épocas, } \\
\text { favorecendo a construção de vocabulário e } \\
\text { repertório relativos às diferentes linguagens } \\
\text { artísticas. }\end{array}$ & $\begin{array}{l}\text { (EF69AR34) Analisar e valorizar o } \\
\text { patrimônio cultural, material e imaterial, de } \\
\text { culturas diversas, em especial a brasileira, } \\
\text { incluindo suas matrizes indígenas, africanas } \\
\text { e europeias, de diferentes épocas, e } \\
\text { favorecendo a construção de vocabulário e } \\
\text { repertório relativos às diferentes linguagens } \\
\text { artísticas. }\end{array}$ \\
\hline $\begin{array}{l}\text { Educação } \\
\text { Física }\end{array}$ & $\begin{array}{l}\text { (EF35EF01) Experimentar e fruir } \\
\text { brincadeiras e jogos populares do Brasil e } \\
\text { do mundo, incluindo aqueles de matriz } \\
\text { indígena e africana, e recriá-los, } \\
\text { valorizando a importância desse patrimônio } \\
\text { histórico cultural. }\end{array}$ & $\begin{array}{l}\text { (EF67EF10) Diferenciar exercício físico de } \\
\text { atividade física e propor alternativas para a } \\
\text { prática de exercícios físicos dentro e fora do } \\
\text { ambiente escolar. }\end{array}$ \\
\hline Ciências & $\begin{array}{l}\text { (EF01CI05) Identificar e nomear diferentes } \\
\text { escalas de tempo: os períodos diários } \\
\text { (manhã, tarde, noite) e a sucessão de dias, } \\
\text { semanas, meses e anos. }\end{array}$ & $\begin{array}{l}\text { (EF06CI12) Identificar diferentes tipos de } \\
\text { rocha, relacionando a formação de fósseis a } \\
\text { rochas sedimentares em diferentes períodos } \\
\text { geológicos. }\end{array}$ \\
\hline Geografia & $\begin{array}{l}\text { (EF04GE11) Identificar as características } \\
\text { das paisagens naturais e antrópicas (relevo, } \\
\text { cobertura vegetal, rios etc.) no ambiente em } \\
\text { que vive, bem como a ação humana na } \\
\text { conservação ou degradação dessas áreas. }\end{array}$ & $\begin{array}{l}\text { (EF06GE11) Analisar distintas interações } \\
\text { das sociedades com a natureza, com base na } \\
\text { distribuição dos componentes físico- } \\
\text { naturais, incluindo as transformações da } \\
\text { biodiversidade local e do mundo. }\end{array}$ \\
\hline
\end{tabular}

Fonte: os autores, 2020.

\section{Central de Captação de Água de Gravatal}

A água é um elemento necessário para a sobrevivência de todos os seres vivos e também no desenvolvimento das atividades humanas. A água para uso humano precisa estar em quantidade e qualidade adequada para a proteção da saúde. A Casan (Companhia Catarinense de Águas e Saneamento) realiza o processo de captação de água para abastecer o município de Gravatal em manancial de superfície rio São Miguel (CASAN, 2014). O processo de captação se dá por meio de uma barragem de nível com intuito de aumentar o volume necessário e a adução é pela energia potencial ou gravidade até a Estação de Tratamento de Água (ETA), situada a $2,9 \mathrm{~km}$, sem necessitar de bombeamento.

A água, ao chegar na ETA, passa por três processos antes de ser distribuída para a população. No trajeto até a Central de Captação, é possível acompanhar o transporte de água dos adutores até a ETA. Como recurso pedagógico, todo esse percurso até chegar na captação, estão sintetizados no Quadro 4.

Quadro 4 - Síntese dos componentes curriculares e habilidades que podem ser desenvolvidos na Central de Captação de Água

\begin{tabular}{|l|c|c|}
\hline \multirow{2}{*}{$\begin{array}{c}\text { Componente } \\
\text { curricular }\end{array}$} & \multicolumn{2}{|c|}{ Habilidades } \\
\cline { 2 - 3 } & Anos Iniciais & Anos Finais \\
\hline
\end{tabular}




\begin{tabular}{|c|c|c|}
\hline Matemática & $\begin{array}{l}\text { (EF04MA16) Descrever deslocamentos e } \\
\text { localização de pessoas e de objetos no } \\
\text { espaço, por meio de malhas quadriculadas e } \\
\text { representações como desenhos, mapas, } \\
\text { planta baixa e croquis, empregando termos } \\
\text { como direita e esquerda, mudanças de } \\
\text { direção e sentido, intersecção, transversais, } \\
\text { paralelas e perpendiculares. }\end{array}$ & $\begin{array}{l}\text { (EF07MA36) Planejar e realizar pesquisa } \\
\text { envolvendo tema da realidade social, } \\
\text { identificando a necessidade de ser censitária } \\
\text { ou de usar amostra, e interpretar os dados } \\
\text { para comunicá-los por meio de relatório } \\
\text { escrito, tabelas e gráficos, com o apoio de } \\
\text { planilhas eletrônicas. }\end{array}$ \\
\hline Ciências & $\begin{array}{l}\text { (EF05CI03) Selecionar argumentos que } \\
\text { justifiquem a importância da cobertura } \\
\text { vegetal para a manutenção do ciclo da água, } \\
\text { a conservação dos solos, dos cursos de água } \\
\text { e da qualidade do ar atmosférico. }\end{array}$ & $\begin{array}{l}\text { (EF09CI13) Propor iniciativas individuais e } \\
\text { coletivas para a solução de problemas } \\
\text { ambientais da cidade ou da comunidade, } \\
\text { com base na análise de ações de consumo } \\
\text { consciente e de sustentabilidade bem- } \\
\text { sucedidas. }\end{array}$ \\
\hline Geografia & $\begin{array}{l}\text { (EF03GE09) Investigar os usos dos } \\
\text { recursos naturais, com destaque para os } \\
\text { usos da água em atividades cotidianas } \\
\text { (alimentação, higiene, cultivo de plantas } \\
\text { etc.), e discutir os problemas ambientais } \\
\text { provocados por esses usos. }\end{array}$ & $\begin{array}{l}\text { (EF06GE11) Analisar distintas interações } \\
\text { das sociedades com a natureza, com base na } \\
\text { distribuição dos componentes físico- } \\
\text { naturais, incluindo as transformações da } \\
\text { biodiversidade local e do mundo. }\end{array}$ \\
\hline
\end{tabular}

Fonte: os autores, 2020.

\section{Pousada do Vô Juca}

A Pousada do Vô Juca é uma propriedade familiar da Dona Edite e Seu Miguel, localizada no bairro São Miguel, herança de geração de seu avô Juca, por isso o nome. Na propriedade tem a casa da família, a pousada, uma piscina e o bar onde tem a comercialização dos produtos como melado, licores, açúcar, cachaças e açudes com peixes. Como na propriedade funcionava uma pousada e o fluxo de turistas era constante, ela possui uma boa infraestrutura para receber os alunos.

Na propriedade do Vô Juca podem ser visitadas diversas construções, como o engenho e o alambique, além de utensílios caseiros utilizados na residência e na agricultura, desde a época da colonização. Ressalta-se que a visita nesta propriedade faz um resgate histórico das memórias, das práticas e modos de vida do passado. No Quadro 5, as propostas de trabalho para a Pousada Vô Juca foram sintetizadas.

Quadro 5 - Síntese dos componentes curriculares e habilidades que podem ser desenvolvidos na Propriedade do Vô Juca

\begin{tabular}{|c|l|l|}
\hline $\begin{array}{c}\text { Componente } \\
\text { curricular }\end{array}$ & \multicolumn{1}{|c|}{ Anobilidades } \\
\cline { 2 - 4 } $\begin{array}{c}\text { Língua } \\
\text { Portuguesa }\end{array}$ & $\begin{array}{l}\text { (EF02LP14) Planejar e produzir pequenos } \\
\text { relatos de observação de processos, de } \\
\text { fatos, de experiências pessoais, mantendo } \\
\text { as características do gênero, considerando a } \\
\text { situação comunicativa e o tema/assunto do } \\
\text { texto. }\end{array}$ & $\begin{array}{l}\text { (EF06LP11) Utilizar, ao produzir texto, } \\
\text { conhecimentos linguísticos e gramaticais: } \\
\text { tempos verbais, concordância nominal e } \\
\text { verbal, regras ortográficas, pontuação etc. }\end{array}$ \\
\hline \multirow{3}{*}{ História } & $\begin{array}{l}\text { (EF03HI08) Identificar modos de vida na } \\
\text { cidade e no campo no presente, } \\
\text { comparando-os com os do passado. }\end{array}$ & $\begin{array}{l}\text { (EF06HI05) Descrever modificaçães da } \\
\text { natureza e da paisagem realizadas por } \\
\text { diferentes tipos de sociedade, com destaque } \\
\text { para os povos indígenas originários e povos }\end{array}$ \\
\hline
\end{tabular}




\begin{tabular}{|c|l|l|}
\hline & \multicolumn{1}{|c|}{} & $\begin{array}{l}\text { africanos, e discutir a natureza e a lógica das } \\
\text { transformações ocorridas. }\end{array}$ \\
\hline Geografia & $\begin{array}{l}\text { (EF03GE11) Comparar impactos das } \\
\text { atividades econômicas urbanas e rurais } \\
\text { sobre o ambiente físico natural, assim como } \\
\text { os riscos provenientes do uso de } \\
\text { ferramentas e máquinas. }\end{array}$ & $\begin{array}{l}\text { (EF08GE02) Relacionar fatos e situações } \\
\text { representativas da história das famílias do } \\
\text { Município em que se localiza a escola, } \\
\text { considerando a diversidade e os fluxos } \\
\text { migratórios da população mundial. }\end{array}$ \\
\hline
\end{tabular}

Fonte: os autores, 2020.

\section{Nascente}

A Nascente está localizada próxima à estrada geral de São Miguel, em meio a mata preservada. No local onde se encontra a nascente, há presença de um microclima, com características de temperatura e umidade específicas da área. Com a água da Nascente, foi improvisado pela comunidade local uma bica d'água. Desta forma, quem passar por esse local, pode beber a água diretamente da Nascente.

Próximo da Nascente tem uma trilha, feita pelos moradores que utilizam suas águas para abastecimento. Por essa trilha pode-se observar o caminho que a água faz, desde a sua nascente, localizada em uma altitude mais elevada do que a bica d'água, até o ponto onde ela fica concentrada. As possibilidades de trabalho que podem ser desenvolvidas na Nascente, estão presentes no Quadro 6.

Quadro 6 - Síntese dos componentes curriculares e habilidades que podem ser desenvolvidos na Nascente.

\begin{tabular}{|c|c|c|}
\hline \multirow{2}{*}{$\begin{array}{l}\text { Componente } \\
\text { curricular }\end{array}$} & \multicolumn{2}{|c|}{ Habilidades } \\
\hline & Anos Iniciais & Anos Finais \\
\hline Ciências & $\begin{array}{l}\text { (EF02CI04) Descrever características de } \\
\text { plantas e animais (tamanho, forma, cor, fase } \\
\text { da vida, local onde se desenvolvem etc.) que } \\
\text { fazem parte de seu cotidiano e relacioná-las } \\
\text { ao ambiente em que eles vivem. }\end{array}$ & $\begin{array}{l}\text { (EF09CI13) Propor iniciativas individuais e } \\
\text { coletivas para a solução de problemas } \\
\text { ambientais da cidade ou da comunidade, } \\
\text { com base na análise de ações de consumo } \\
\text { consciente e de sustentabilidade bem- } \\
\text { sucedidas. }\end{array}$ \\
\hline Geografia & $\begin{array}{l}\text { (EF02GE11) Reconhecer a importância do } \\
\text { solo e da água para a vida, identificando } \\
\text { seus diferentes usos (plantação e extração } \\
\text { de materiais, entre outras possibilidades) e } \\
\text { os impactos desses usos no cotidiano da } \\
\text { cidade e do campo. } \\
\text { (EF03GE10) Identificar os cuidados } \\
\text { necessários para utilização da água na } \\
\text { agricultura e na geração de energia de modo } \\
\text { a garantir a manutenção do provimento de } \\
\text { água potável. }\end{array}$ & $\begin{array}{l}\text { (EF06GE04) Descrever o ciclo da água, } \\
\text { comparando o escoamento superficial no } \\
\text { ambiente urbano e rural, reconhecendo os } \\
\text { principais componentes da morfologia das } \\
\text { bacias e das redes hidrográficas e a sua } \\
\text { localização no modelado da superfície } \\
\text { terrestre e da cobertura vegetal. } \\
\text { (EF06GE12) Identificar o consumo dos } \\
\text { recursos hídricos e o uso das principais } \\
\text { bacias hidrográficas no Brasil e no mundo, } \\
\text { enfatizando as transformações nos } \\
\text { ambientes urbanos. }\end{array}$ \\
\hline
\end{tabular}

Fonte: os autores, 2020. 


\section{Gruta Nossa Senhora da Saúde}

A Gruta Nossa Senhora da Saúde é uma gruta de origem natural, formada por matacões graníticos imbricados da formação Granito Imaruí-Capivari. O granito encontra-se em processo de intemperização e com erosão, por isso nas fraturas se desenvolvem vegetação. Anualmente, no mês de maio, é organizada na Gruta a festa tradicional da padroeira "Nossa Senhora da Saúde", onde muitos fiéis e a população da comunidade se deslocam até São Miguel.

Por ter a forma de um abrigo sobre rocha, a parte interna dessa gruta foi construída pela população em 1957, com o sentimento de pertencimento dos primeiros moradores, com intuito de criar um local para exercer a sua religiosidade. É a única gruta deste porte na comunidade de São Miguel. Por esses motivos, este é um ponto de interesse para se trabalhar as memórias, o patrimônio natural e demais temas, representados no Quadro 7.

Quadro 7 - Síntese dos componentes curriculares e habilidades que podem ser desenvolvidos na Gruta Nossa Senhora da Saúde.

\begin{tabular}{|c|c|c|}
\hline \multirow{2}{*}{$\begin{array}{l}\text { Componente } \\
\text { curricular }\end{array}$} & \multicolumn{2}{|c|}{ Habilidades } \\
\hline & Anos Iniciais & Anos Finais \\
\hline História & $\begin{array}{l}\text { (EF03HI04) Identificar os patrimônios } \\
\text { históricos e culturais de sua cidade ou } \\
\text { região e discutir as razões culturais, sociais } \\
\text { e políticas para que assim sejam } \\
\text { considerados. }\end{array}$ & $\begin{array}{l}\text { (EF06HI05) Descrever modificações da } \\
\text { natureza e da paisagem realizadas por } \\
\text { diferentes tipos de sociedade, com } \\
\text { destaque para os povos indígenas } \\
\text { originários e povos africanos, e discutir a } \\
\text { natureza e a lógica das transformações } \\
\text { ocorridas. }\end{array}$ \\
\hline $\begin{array}{c}\text { Ensino } \\
\text { Religioso }\end{array}$ & $\begin{array}{l}\text { (EF03ER01) Identificar e respeitar os } \\
\text { diferentes espaços e territórios religiosos } \\
\text { de diferentes tradições e movimentos } \\
\text { religiosos. } \\
\text { (EF03ER02) Caracterizar os espaços e } \\
\text { territórios religiosos como locais de } \\
\text { realização das práticas celebrativas. }\end{array}$ & $\begin{array}{l}\text { (EF06ER06) Reconhecer a importância } \\
\text { dos mitos, ritos, símbolos e textos na } \\
\text { estruturação das diferentes crenças, } \\
\text { tradições e movimentos religiosos. }\end{array}$ \\
\hline
\end{tabular}

Fonte: os autores, 2020.

O local possui um espaço amplo ao ar livre, possui estacionamento, local para fazer as refeições, banheiros, água e sinalização por todo o percurso, desde a estrada principal pavimentada.

\section{Casarão de Colonização italiana}

De colonização italiana de aproximadamente 120 anos, o Casarão é uma das construções restantes no município que remetem à colonização italiana, pertencente a família de Estevão Grasso, uma das a colonizar Gravatal. Não se tem registros concretos da 
construção do Casarão, mas sabe-se que ela é mais antiga que a Igreja da comunidade que tem 100 anos.

A comunidade de São Miguel, onde se encontra o Casarão, era bem habitada. Haviam muitos engenhos de farinha, açúcar e olarias que movimentavam a economia da época. Com a chegada da fumicultura muitas famílias deixam comunidade, devido às mudanças ocorridas no campo, e com a falência da pequena agricultura, houve o êxodo rural e muitas famílias desceram o morro para tentar a vida em municípios próximos.

A propriedade conserva a pintura original no interior da residência, que remete ao período que serviu de moradia para os colonizadores. A parte externa passou por pequenas reformas que preservaram a cor original. No Casarão, podem ser trabalhados diversos temas, descritos no Quadro 8.

Quadro 8 - Síntese dos componentes curriculares e habilidades que podem ser desenvolvidos no Casarão de colonização italiana

\begin{tabular}{|c|c|c|}
\hline \multirow{2}{*}{$\begin{array}{l}\text { Componente } \\
\text { curricular }\end{array}$} & \multicolumn{2}{|c|}{ Habilidades } \\
\hline & Anos Iniciais & Anos Finais \\
\hline Artes & $\begin{array}{l}\text { (EF15AR25) Conhecer e valorizar o } \\
\text { patrimônio cultural, material e imaterial, de } \\
\text { culturas diversas, em especial a brasileira, } \\
\text { incluindo-se suas matrizes indígenas, } \\
\text { africanas e europeias, de diferentes épocas, } \\
\text { favorecendo a construção de vocabulário e } \\
\text { repertório relativos às diferentes linguagens } \\
\text { artísticas. }\end{array}$ & $\begin{array}{l}\text { (EF69AR34) Analisar e valorizar o } \\
\text { patrimônio cultural, material e imaterial, de } \\
\text { culturas diversas, em especial a brasileira, } \\
\text { incluindo suas matrizes indígenas, africanas } \\
\text { e europeias, de diferentes épocas, e } \\
\text { favorecendo a construção de vocabulário e } \\
\text { repertório relativos às diferentes linguagens } \\
\text { artísticas. }\end{array}$ \\
\hline História & $\begin{array}{l}\text { (EF03HI04) Identificar os patrimônios } \\
\text { históricos e culturais de sua cidade ou } \\
\text { região e discutir as razões culturais, sociais } \\
\text { e políticas para que assim sejam } \\
\text { considerados. } \\
\text { (EF03HI08) Identificar modos de vida na } \\
\text { cidade e no campo no presente, } \\
\text { comparando-os com os do passado. }\end{array}$ & $\begin{array}{l}\text { (EF06HI05) Descrever modificações da } \\
\text { natureza e da paisagem realizadas por } \\
\text { diferentes tipos de sociedade, com destaque } \\
\text { para os povos indígenas originários e povos } \\
\text { africanos, e discutir a natureza e a lógica das } \\
\text { transformações ocorridas. }\end{array}$ \\
\hline Geografia & $\begin{array}{l}\text { (EF04GE01) Selecionar, em seus lugares de } \\
\text { vivência e em suas histórias familiares e/ou } \\
\text { dacomunidade, elementos de distintas } \\
\text { culturas (indígenas, afro-brasileiras, de } \\
\text { outras regiões do país, latino-americanas, } \\
\text { europeias, asiáticas etc.), valorizando o que } \\
\text { é próprio em cada uma delas e sua } \\
\text { contribuição para a formação da cultura } \\
\text { local, regional e brasileira. }\end{array}$ & $\begin{array}{l}\text { (EF08GE02) Relacionar fatos e situações } \\
\text { representativas da história das famílias do } \\
\text { Município em que se localiza a escola, } \\
\text { considerando a diversidade e os fluxos } \\
\text { migratórios da população mundial. }\end{array}$ \\
\hline
\end{tabular}

Fonte: os autores, 2020.

\section{Mirante Tataywarê}


O Mirante Tataywarê está localizado em um dos pontos de maior altitude $(352 \mathrm{~m})$ do município, na comunidade de São Miguel, sendo o único mirante de Gravatal, inaugurado no ano de 2015. Recebeu o nome de Tataywarê, que em tupi-guarani significa "fogo no céu", fazendo uma homenagem às populações Xokleng que ali viviam. É um dos pontos turísticos mais procurados do município, por estar em um local estratégico com uma vista panorâmica desde o planalto catarinense até o litoral.

O monumento presente no mirante é uma representação da Bromélia Gravatá. Segundo registros de Travassos (1992), é a representação da Bromélia Gravatá, dado pelos imigrantes açorianos, o primeiro nome do município "Gravatá", que posteriormente passou a se chamar Gravatal. O mirante tem um grande espaço livre e nele podem-se realizar rodas de conversa e contação de histórias, além e outros assuntos sintetizados no Quadro 9.

Quadro 9 - Síntese dos componentes curriculares e habilidades que podem ser desenvolvidos no mirante Tataywarê

\begin{tabular}{|c|c|c|}
\hline \multirow{2}{*}{$\begin{array}{l}\text { Componente } \\
\text { curricular }\end{array}$} & \multicolumn{2}{|c|}{ Habilidades } \\
\hline & Anos Iniciais & Anos Finais \\
\hline Matemática & $\begin{array}{l}\text { (EF05MA14) Utilizar e compreender } \\
\text { diferentes representações para a localização } \\
\text { de objetos no plano, como mapas, células } \\
\text { em planilhas eletrônicas e coordenadas } \\
\text { geográficas, a fim de desenvolver as } \\
\text { primeiras noções de coordenadas } \\
\text { cartesianas. }\end{array}$ & $\begin{array}{l}\text { (EF06MA28) Interpretar, descrever e } \\
\text { desenhar plantas baixas simples de } \\
\text { residências e vistas aéreas. }\end{array}$ \\
\hline Geografia & $\begin{array}{l}\text { (EF05GE04) Reconhecer as características } \\
\text { da cidade e analisar as interações entre a } \\
\text { cidade e o campo e entre cidades na rede } \\
\text { urbana. }\end{array}$ & $\begin{array}{l}\text { (EF04GE01) Selecionar, em seus lugares de } \\
\text { vivência e em suas histórias familiares e/ou } \\
\text { da comunidade, elementos de distintas } \\
\text { culturas (indígenas, afro-brasileiras, de } \\
\text { outras regiões do país, latino-americanas, } \\
\text { europeias, asiáticas etc.), valorizando o que } \\
\text { é próprio em cada uma delas e sua } \\
\text { contribuição para a formação da cultura } \\
\text { local, regional e brasileira. }\end{array}$ \\
\hline História & $\begin{array}{l}\text { (EF03HI08) Identificar modos de vida na } \\
\text { cidade e no campo no presente, } \\
\text { comparando-os com os do passado. }\end{array}$ & $\begin{array}{l}\text { (EF09HI05) Identificar os processos de } \\
\text { urbanização e modernização da sociedade } \\
\text { brasileira e avaliar suas contradições e } \\
\text { impactos na região em que vive. }\end{array}$ \\
\hline Ciências & $\begin{array}{l}\text { (EF03CI08) Observar, identificar e registrar } \\
\text { os períodos diários (dia e/ou noite) em que } \\
\text { o Sol, demais estrelas, Lua e planetas estão } \\
\text { visíveis no céu. }\end{array}$ & $\begin{array}{l}\text { (EF09CI15) Relacionar diferentes leituras } \\
\text { do céu e explicações sobre a origem da } \\
\text { Terra, do Sol ou do Sistema Solar às } \\
\text { necessidades de distintas culturas } \\
\text { (agricultura, caça, mito, orientação espacial } \\
\text { e temporal etc.). }\end{array}$ \\
\hline
\end{tabular}

Fonte: os autores, 2020 
Por estar situado em um ponto de alta altitude e com uma de todo o município, é possível observar o sol, a lua, as estrelas e no período da noite as várias constelações e mistérios que o céu esconde, em razão da pouca iluminação. Atualmente, o mirante conta com banheiros, lixeiras e sinalização.

\section{CONSIDERAÇÕES FINAIS}

O turismo rural pedagógico é uma ferramenta metodológica que permite aos estudantes visualizarem o conteúdo da sala de aula na sua realidade. Pretende-se, por meio deste roteiro de turismo rural pedagógico, fornecer subsídios para os estudantes vivenciarem a rotina, ao adquirirem novos conhecimentos e informações sobre o espaço rural. Para a comunidade receptora do turismo rural pedagógico também significa a esperança para a melhoria de infraestrutura, economia e a preservação e conservação dos patrimônios naturais e culturais.

Para auxiliar o trabalho dos professores, foi confeccionado para cada ponto um quadro com os componentes curriculares e as habilidades que podem ser desenvolvidas, separadas por anos iniciais e anos finais do Ensino Fundamental, além de outro quadro sugestivo disponibilizado em forma de link. Desta forma, os professores podem se organizar e adequar este roteiro com o calendário escolar. É importante frisar que este roteiro não é restrito somente a este público, podendo sofrer adaptações para todos os níveis de ensino.

Este roteiro levou em consideração um recorte do município, a comunidade de São Miguel. Porém, Gravatal apresenta potencial para o desenvolvimento de diversos roteiros envolvendo práticas pedagógicas. Contudo, para que isso aconteça é necessário levar as escolas a conhecerem esses espaços e perceberem as contribuições do turismo rural pedagógico no aprendizado dos estudantes. Para isso, pretende-se divulgar o roteiro desenvolvido as escolas do município, bem como na Secretaria Municipal de Educação e na Secretaria de Turismo de Gravatal e de municípios vizinhos.

\section{REFERÊNCIAS}

ANDRADE, José Vicente de. Turismo: fundamentos e dimensões. São Paulo: Ática, 2000. BRASIL. MINISTÉRIO DA EDUCAÇÃO. Base Nacional Comum Curricular. 2017. BRASIL, Ministério do Turismo. Diretrizes para o Desenvolvimento do Turismo Rural no Brasil. Brasília: Ministério do Turismo, 2003.

BRASIL, Secretaria Nacional de Políticas de Turismo. Programa de Regionalização do Turismo - Roteiros do Brasil. Brasília: Ministério do Turismo, 2006.

CAMPOS, Nazareno José de. Terras de uso comum no Brasil: abordagem histórico socioespacial. Florianópolis: Editora da UFSC, 2011. 
CASAN. Relatório anual de qualidade da água distribuída. 2014. Disponível em: https://www.casan.com.br/ckfinder/userfiles/files/rel_anu_qual_agua_2014/srs/laguna/grav atal.pdf. Acesso em: 22 jun. 2020.

CRUZ, Rita de Cássia Ariza da. Introdução à geografia do turismo. 2. ed São Paulo: Roca, 2003.

CPRM. Programa levantamentos geológicos básicos do Brasil: Carta geológica. Brasil, 2000. 1 carta topográfica, color. Escala 1:250.000. Projeção UTM. $10.000 \mathrm{~km}$ e $500 \mathrm{~km}$, respectivamente. Folha Criciúma - SH.22-X-B.

DUARTE, Marisaura Medeiros. Gravatá, uma volta ao passado. Florianópolis: IOESC, 2001.

FARIAS, Deisi Scunderlick Eloy de. Distribuição e padrão de assentamento - propostas para os sítios da tradição umbu na encosta de Santa Catarina. 2005. 102 f. Tese (Doutorado) - Curso de Pós-graduação em História, Faculdade de Filosofia e Ciências Humanas da PUC-RS, Porto Alegre, 2005.

FECAM. Acesso à Informação Federação Catarinense de Municípios. FECAM, SANTA CATARINA, 28 de out. De 2019. Disponível em: https:// https://lai.fecam.org.br/. Acesso em: 21 de abr. de 2020.

GRAVATAL. (2014) Plano municipal de Saneamento Básico. Prefeitura de Gravatal. Disponível

em https://static.fecam.net.br/uploads/641/arquivos/611275_Plano_municipal_de_Saneamento _Basico_.pdf. Acesso em: 02 jun. 2020.

IBGE. Gravatal: população. 2020. Disponível em: https://cidades.ibge.gov.br/brasil/sc/gravatal/panorama. Acesso em: 06 set. 2020.

IBGE. Nível geográfico: população por situação de domicílio (população presente e residente. 2010.2 Disponível https://seriesestatisticas.ibge.gov.br/series.aspx?no=6\&op=1\&vcodigo=CD91\&t=populaca o-situacao-domicilio-populacao-presente-residente. Acesso em: 25 ago. 2020.

KLEIN, Angela Luciane; TROIAN, Alessandra; SOUZA, Marcelino de. O turismo rural pedagógico e a educação ambiental: as ações pedagógicas desenvolvidas na fazenda quinta da estância grande - Viamão (RS). Revista Eletrônica do Mestrado em Educação Ambiental, Rio Grande do Sul, v. 27, n. 1517-1256, p. 107-121, dez. 2011.

LINGNER, Débora Vanessa; SCHORN, Lauri Amândio; SEVEGNANI, Lucia; GASPER, André Luís de; MEYER, Leia; VIBRANS, Alexander Christian. Floresta ombrófila densa de Santa Catarina - Brasil: agrupamento e ordenação baseados em amostragem sistemática. Ciência Florestal, Santa Maria, v. 25, n. 4, p.933-946, 2015.

MATOS, Francisco de Castro. Turismo Pedagógico: o estudo do meio como ferramenta fomentadora do currículo escolar. In: Seminário de Pesquisa em Turismo do Mercosul, 7. , 2012, Caxias do Sul. Anais do VII Seminário de Pesquisa em Turismo do Mercosul. Caxias do Sul: Universidade de Caxias do Sul, 2012. p. 1 - 11.

PEREIRA, Fábia de Melo; LOPES, Maria Teresa do Rêgo; CAMARGO, Ricardo Costa Rodrigues de; VILELA, Sérgio Luis de Oliveira. Raças. 2003. Disponível em: https://www.agencia.cnptia.embrapa.br/gestor/territorio_sisal/arvore/CONT000fckg3dhb02 wx5eo0a2ndxyu6qshyx.html. Acesso em 03 jul. 2020.

PERINOTTO, André Riani Costa. Turismo pedagógico: uma ferramenta para educação ambiental. Caderno Virtual de Turismo, Rio de Janeiro, v. 8, n. 1, p. 100-103, jan. 2008. SALVADOR, Joelson Claudino. Potencialidades e desafios do turismo no município de Gravatal, Santa Catarina. 2019. Trabalho de Conclusão de Curso (Graduação em Geografia) - Universidade do Sul de Santa Catarina, Tubarão, 2019. 
SANTA CATARINA. Secretaria de Estado do Desenvolvimento Urbano e Meio Ambiente do Estado de Santa Catarina. Plano integrado de recursos hídricos da bacia hidrográfica do rio Tubarão e Complexo Lagunar. Porto Alegre: EPT, 2002, v. 7B. 9p.

SCHMITZ, Pedro Ignácio. A ocupação pré-histórica do estado de Santa Catarina. Tempos Acadêmicos, Criciúma, v. 01, n. 11, p. 06-24, 2013.

SCREMIN, Juliane; JUNQUEIRA, Sérgio; Aprendizado diferenciado: turismo pedagógico no âmbito escolar. Caderno de estudos e pesquisas em turismo, Curitiba, v. 1, p. 26-42, dez. 2012.

SEBRAE /SC. Caderno de Desenvolvimento de Santa Catarina: Gravatal. 2016. Disponível em: https://datasebrae.com.br/municipios/sc/m/Gravatal\%20\%20Cadernos\%20de\%20Desenvol vimento.pdf. Acesso em: 21 de abr. 2020.

SILVEIRA, Cibele Rossana Funck Donato da; MARTINS, Patrícia Cristina Statella; VIEIRA, Fernanda Sá. Turismo Pedagógico em Dourados /MS- Uma atividade educacional. In: Seminário de Pesquisa em Turismo do Mercosul, 5., 2008, Caxias do Sul. Trabalhos. Caxias do Sul: UCS, 2008. p. 01-12.

TRAVASSOS, Vladimir; PALMEIRA, Luis. Gravatal: um pouco de sua história. Florianópolis: Paralelo 27, 1992.

VEADO, Ricardo Wagner ad-Víncula; PIMENTA, Luiz Henrique Fragoas. Vegetação e uso da terra. In: ROCHA, Isa de Oliveira. (Org.). Atlas geográfico de Santa Catarina: diversidade da natureza. 2. ed. Florianópolis: Udesc, 2016. p. 161-172.

VIBRANS, Alexander Christian. ROBERTS, Ronald E. Mcroberts ; MOSER, Paolo, NICOLETTI, Adilson Luiz. How much remains of the Brazilian Atlantic forest in the state of Santa Catarina? Assessing the accuracy of forest cover maps using ground data from the Santa Catarina Forest and Floristic Inventory. Remote Sensing of Environment, Colombo, 2012.

ZANONI, Juliano; STEFANO, Silvio Roberto. Desenvolvendo o turismo rural em um meio de hospedagem rural: Spa Xangrilá. In: Seminário em Administração FEA-USP, 7., 2004, São Paulo. Anais [...]. São Paulo: USP, 2004. p. 1-11. 